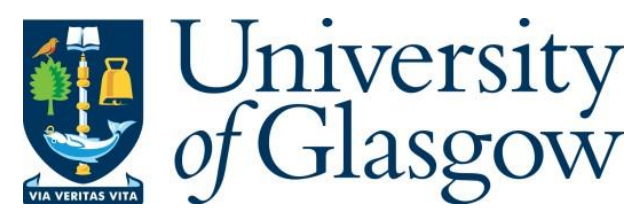

Sloan, M. A., Aghabi, D. and Harding, C. R. (2021) Orchestrating a heist: uptake and storage of metals by apicomplexan parasites. Microbiology, 167(12), 001114.

There may be differences between this version and the published version. You are advised to consult the publisher's version if you wish to cite from it.

http://eprints.gla.ac.uk/258219/

Deposited on: 6 January 2022

Enlighten - Research publications by members of the University of Glasgow http://eprints.gla.ac.uk 


\section{Orchestrating a Heist: Uptake and Storage of Metals by}

\section{Apicomplexan Parasites}

Wellcome Centre for Integrative Parasitology, Institute for Infection, Immunity and Inflammation, University of Glasgow, UK

*Corresponding author: clare.harding@glasgow.ac.uk

\section{Introduction}

The acquisition and storage of metals has been a preoccupation of life for millennia. Transition metals, in particular iron, copper, and zinc, have vital roles within cells. However, metals also make dangerous cargos; inappropriate uptake or storage of transition metals leads to cell death. This paradox has led to cells developing elegant and frequently redundant mechanisms for fine-tuning local metal concentrations. In the context of infection, pathogens must overcome further hurdles, as hosts act to weaponize metal availability

The Apicomplexa are a broad family of obligate intracellular eukaryotic parasites infecting a range of hosts from marine invertebrates to mammals. The best studied Apicomplexa are; Plasmodium spp., cause of malaria, one of the most deadly infectious diseases; Toxoplasma gondii, a ubiquitous pathogen of warmblooded animals which causes miscarriage and blindness; and Cryptosporidium spp., a leading cause of diarrheal mortality in children under 5. The Apicomplexa share key metabolic and structural features including; residence within membrane-bound parasitophorous vacuole in the cytoplasm of the host cell; a single mitochondrion (although this has been lost in Cryptosporidium spp.); an apicoplast - a relic plastid which retains a number of essential metabolic pathways, and specialised secretory organelles which make up the apical complex for which the phylum is named transmission (Harding and Frischknecht, 2020; Jacot et al., 2016; Striepen et al., 2007). Apicomplexa also share complex, multi-host lifecycles, although with large variation in hosts and methods of. Plasmodium is taken up from infected hosts by mosquitoes in a 
blood meal where it completes its sexual lifecycle. Mosquitos then inject the parasite back into the mammalian host where it passes through the liver before returning to asexual replication and expansion within red blood cells (Aly et al., 2009; Venugopal et al., 2020). In contrast, Toxoplasma gondii replicates within all cell types and tissues and forms slow-growing cysts within brain and muscle tissue. Upon ingestion of cysts by cats, $T$. gondii completes its sexual lifecycle, resulting in excretion of oocysts which are orally infectious to humans and most mammals (Martorelli Di Genova and Knoll, 2020). Cryptosporidium is also acquired from consumption of oocysts which enter and infect the gut. Unusually for the Apicomplexa, Cryptosporidium completes its entire lifecycle in the gut of one host, resulting in the excretion of oocysts (Tandel et al., 2019).

Here, we summarise the existing work on iron, zinc and copper in the context of apicomplexan parasites, focusing on the transporters required. Each metal presents distinct challenges to the parasite, e.g. exchangeable iron is a potential source of dangerous reactive oxygen species and available copper is almost non-existent within mammalian hosts. However, by summarising what is known about metal transport in these organisms, we hope to provide a basis for further study of this fascinating topic.

\section{Iron ingress and imprisonment}

Iron is an essential nutrient for the vast majority of known organisms where it plays a crucial role in core processes including oxidative phosphorylation and DNA replication and repair. Iron is primarily utilized by cells as part of either haem (Kloehn et al., 2020), iron sulphur (Fe-S) clusters (Dellibovi-Ragheb et al., 2013; LaGier et al., 2003) or diiron group cofactors (Yamasaki et al., 2021).

The importance of iron to the growth of apicomplexan parasites during mammalian infection is well known. Iron supplementation in mice was shown to increase P. yoelii burden in the liver (Goma et al., 1996), while iron deficiency may be associated with reduced risk of malaria, though the choice of markers used (e.g. ferritin saturation) impacts risk estimates (Muriuki et al., 2019). Additionally, treatment with iron chelators has been shown to suppress parasite growth in vitro and in vivo (Ferrer et al., 2012; Pollack et al., 1987; Thipubon et al., 2015). However, a mechanism for this is not well understood, as the therapeutic effects appear variable with infection stage and host as well as the chelator and its mode of administration (Bunnag et al., 1992; Ferrer et al., 2012; Gordeuk et al., 1992; Portugal et al., 2011; Thuma et al., 1998). Plasmodium spp. also require iron in their mosquito host, and iron accumulation in the mosquito has been linked to mosquito infection susceptibility (Maya-Maldonado et al., 2021). In T. gondii, iron has been shown to be important in parasite replication and pathogenesis in vitro and in vivo (Almeida et al., 2019; Dimier and Bout, 1998; Mahmoud, 1999; Oliveira et al., 2020) although there have been no clinical studies. There has also been little work on the importance of iron to Cryptosporidium, although anaemia was not associated with 
Cryptosporidium prevalence in one trial (Mengist et al., 2015). Due to the lack of the respiratory chain in Cryptosporidium, it is likely that the parasite's iron requirements are lower than other Apicomplexa, although iron is likely still required by the parasite (Kloehn et al., 2020; LaGier et al., 2003; Miller et al., 2018).

Acquisition of iron is non-trivial. In an oxygen-containing environment, iron is readily oxidised to the ferric $\left(\mathrm{Fe}^{3+}\right)$ form which is poorly soluble at physiological $\mathrm{pH}$ and therefore not readily available for uptake. As obligate intracellular pathogens, any iron must be subverted from the host, however a conserved host defence is to limit available iron, known as nutritional immunity. These interactions are important as iron availability is often a key determinant of infection outcome (Clark et al., 2014; Dimier and Bout, 1998; Oliveira et al., 2020). There are two main options for the Apicomplexa to acquire host iron, the parasites could take up and recycle host iron-containing proteins, or they could directly access the host labile iron pool (LIP), a pool of exchangeable iron only loosely bound to small molecules in the cytoplasm. Despite its abundance in its erythrocyte hosts, Plasmodium do not appear to access iron from haemoglobin, or other host-haem containing proteins, as they lack functional haem oxygenase (Sigala et al., 2012). Instead, Plasmodium uses haemoglobin catabolism as a source of amino acids (Liu et al., 2006), and the majority of host haem is crystallised into hemozoin. Plasmodium appears to utilise host cell haem directly, as haem biosynthesis enzymes are dispensable in blood stage parasites (Kloehn et al., 2021; Nagaraj et al., 2013; Sigala et al., 2015). In contrast, T. gondii also ingests host cell material during infection (Dou et al., 2014), however does not appear able to use exogenous haem (Bergmann et al., 2020) and the digestion of iron-containing proteins has not been confirmed (Kloehn et al., 2021). The form of iron that the parasites can use is also important. Many species encode ferric reductases (Andrews et al., 2003; Arosio et al., 2017; Zaidi et al., 2017; Zhang et al., 2019) such as FRE2/3 from yeast, which can reduce ferric $\left(\mathrm{Fe}^{3+}\right)$ to ferrous $\left(\mathrm{Fe}^{2+}\right)$ iron prior to transport or use. There is no evidence of any ferric reductases in the apicomplexan genomes, suggesting that the parasites take up a source of ferrous iron directly.

The host cell LIP makes an attractive source for parasite iron as it is likely that pores, formed in the parasitophorous vacuolar membrane by parasite proteins (Garten et al., 2018; Gold et al., 2015), could permit iron from the LIP to enter the parasitophorous vacuole. From the intravacuolar space, iron could then be moved into the parasite by specific transporters. A member of the ZIP family of divalent metal iron transporters, named ZIPCO, was localised to the plasma membrane and shown to be required for growth of liver stage $P$. berghei (Sahu et al., 2014). This growth defect could be rescued by supplementation by iron and zinc, suggesting there is some redundancy in the iron acquisition strategies employed by this parasite (Sahu et al., 2014). However, ZIPCO was only expressed in liver stage parasites, and it remains unclear how other parasite stages acquire iron. ZIPCO is conserved between the apicomplexans, including in $T$. gondii where it is predicted to be essential, although has not yet been characterised. 
101 ZIPCO remains the only characterised apicomplexan transporter with a predicted role in iron uptake. 102 However, apicomplexan genomes contain homologues for transporters which have been well characterised 103 in other systems, including the conserved divalent metal iron transporter 1 (DMT1). DMT1 facilitates import 104 of ferrous iron, and other metal ions, into the cell in many systems, including other protozoan parasites 105 (Ballesteros et al., 2018; Smyth et al., 2006), and as such may play a similar role in apicomplexans. The 106 mechanisms of iron uptake are likely of significant importance to the parasites. Most prokaryotic and 107 eukaryotic species encode several distinct pathways for iron uptake, e.g. the distantly related intravacuolar 108 parasite Leishmania mexicana has at least three identified system for taking up iron, either directly or through 109 haem uptake and digestion (Zaidi et al., 2017). For T. gondii, which can replicate in any cell type with 110 differing levels of available iron, fine control of iron uptake would be essential to maintain growth. The 111 limited number of metal transporters identifiable from the genome sequences (Table 1) suggests that these 112 pathways differ significantly from characterised pathways from model organisms,

Intracellular transport and detoxification of iron

The redox potential of iron which makes it so useful also presents a problem. The reaction of iron with oxygen-containing molecules results in the production of damaging reactive oxygen species (Dixon and 118 Stockwell, 2014). As such the level and distribution of iron within cells must be carefully controlled. 119 Mammals, plants and bacteria use the iron-binding protein ferritin (or similar proteins) to store iron in the cytoplasm, however, no ferritin homologs have been found in apicomplexans. Yeast and plants have a 121 different approach to iron storage. Iron is stored in organelles or vacuolar compartments (Li et al., 2001; 122 Sorribes-Dauden et al., 2020; Kim et al., 2006; Roschzttardtz et al., 2009; Zhang et al., 2012). This strategy makes use of membrane transporters to facilitate ferrous iron crossing organelle membranes, likely via a proton-driven antiport mechanism (Kato et al., 2019). Apicomplexan genomes contain homologs for several of these transporters including vacuolar iron transporter (VIT) (Labarbuta et al., 2017; Sharma et al., 2021; Slavic et al., 2016). In P. falciparum, VIT is expressed throughout the parasite life cycle. Parasites lacking VIT exhibited reduced parasitaemia and liver stage development, contained more exchangeable iron and were more sensitive to iron stress (Slavic et al., 2016). Interestingly, Plasmodium VIT appears specific for ferrous iron, while VIT from other organisms are less selective (Sharma et al., 2021; Slavic et al., 2016) suggesting the need for of further metal transporters. These results were corroborated recently in $T$. gondii, where VIT was 131 required for survival under iron stress and to maintain iron stores in the parasite. In T. gondii, VIT was also 132 shown to be important in vivo, highlighting the role of iron storage in pathogenesis (Aghabi et al., 2021). 133 Interestingly, the localization of VIT appears to differ between the species, in Plasmodium VIT localised to 134 the ER (Slavic et al., 2016) while in T. gondii VIT had a highly dynamic, vesicular localization similar to that 
of the vacuolar compartment (Aghabi et al., 2021). This may show differences in iron storage between the species, possibly due to the abundance of iron in haem available to Plasmodium. Iron also needs to be mobilised from intracellular stores, through the action of transporters. Apicomplexa encode a conserved 138 NRAMP homologue which may play a role in iron mobilisation from vacuolar stores (Nevo and Nelson, 2006). Interestingly, this gene is dispensable in $T$. gondii but essential in $P$. falciparum, perhaps underlining the differential importance of iron mobilisation in these cell types (Sidik et al., 2016; Zhang et al., 2019). The mitochondrion, the location of haem and Fe-S biosynthesis, is one of the primary destinations for iron within the cell. Iron is likely moved into the mitochondrion using the homolog of the yeast mitochondrial iron transporter Mrs3/4, mitoferrin, which is conserved in both Toxoplasma and Plasmodium genomes (Table 1) and likely essential, although yet to be characterised.

There remain several open questions as to how iron is moved into other cellular spaces (outlined in Fig. 1). Iron transporters into the Golgi and secretory system have been identified in other organisms (Seo et al., 2012; Xiao et al., 2014) and may also exist in the Apicomplexa. Intriguingly, a ZIP (Zip- Irt- like) metal transporter, likely to transport iron and/or zinc (Table 2) is predicted to be localized to the rhoptries, specialized secretory organelles used by apicomplexan parasites in the process of invasion. There is no known use for iron or zinc in this compartment which underlines the potential new metal biology still to be discovered in this phylum. Further, the apicoplast contains a dedicated Fe-S biogenesis pathway, essential for organelle maintenance and parasite survival (Charan et al., 2017; Gisselberg et al., 2013). The apicoplast, an essential organelle of secondary endosymbiosis, has long been an attractive therapeutic target for apicomplexan disease. However, despite its requirement for iron, there has been no identification of the transporters required to bring iron across the four membranes of the apicoplast, and as such identification of the mechanism of iron transport would be of particular interest.

\section{Iron regulation}

Whilst the networks which regulate host iron content are well described in other organisms (see (Wang and Pantopoulos, 2011) for an excellent review), regulation of iron uptake and storage in Apicomplexa is not well understood. Mammals regulate iron uptake and storage through aconitase (Alén and Sonenshein, 1999; Marondedze et al., 2016; Tang and Guest, 1999), a dual function enzyme/RNA-binding protein which can interact with stem-loop structures called iron responsive elements (IREs), found in specific mRNAs (Hentze et al., 1987; Koeller et al., 1989). Depending on IRE position, this stabilises or destabilises the mRNA, influencing translation. There is some data to suggest that Plasmodium may employ a similar system. $P$. falciparum aconitase has been demonstrated to bind both host (Loyevsky et al., 2001) and parasite IREs 
mammalian counterparts and the utility of this system in the Apicomplexa is currently unknown. There are also some intriguing hints that Apicomplexa may be able to alter the iron homeostasis of their hosts, infection with $T$. gondii resulted in changes in host transferrin levels by stabilization of the IRE (Gail et al., 2004). T. gondii secretes a number of effector proteins into the host cell which have significant effects on host cell transcription (Hakimi et al., 2017) and it is possible that infection subverts host cell iron homeostasis to benefit the parasite, however this requires further investigation.

178 While iron is one of the most abundant metals within cells, its uptake, mobility and regulation have not yet 179 been well studied in the Apicomplexa. Initial studies have demonstrated that iron is essential, however many of the molecular details remain to be discovered. Plasmodium presents an interesting case study, as it faces various iron stresses throughout its lifecycle and requires strategies to both detoxify the abundant iron in the bloodstream form, and acquire enough iron in the mosquito to power replication. By examining iron uptake, usage and regulation in these divergent eukaryotes, we have the opportunity to discover new biology, as well as novel vulnerabilities for future treatment.

\begin{tabular}{|c|c|c|c|c|c|c|c|}
\hline \multicolumn{5}{|c|}{ P. falciparum } & \multicolumn{3}{|l|}{ T. gondii } \\
\hline Type & $\begin{array}{l}\text { Gene } \\
\text { name }\end{array}$ & Pf ID & Phenotype & Localisation & $\mathrm{Tg}$ ID & $\begin{array}{l}\text { Phenotype } \\
\text { score }\end{array}$ & $\begin{array}{l}\text { Localisation } \\
\text { prediction }\end{array}$ \\
\hline \multirow[t]{5}{*}{ Transporter } & NRAMP & PF3D7_0523800 & Essential & - & TGME49_267270 & 0.49 & - \\
\hline & VIT1 & PF3D7_1223700 & Dispensable & $\begin{array}{l}\text { ER (Slavic et } \\
\text { al., 2016) }\end{array}$ & TGME49_266800 & -1.22 & $\begin{array}{l}\text { Vacuolar/ } \\
\text { vesicular } \\
\text { (Aghabi et al., } \\
\text { 2021) }\end{array}$ \\
\hline & ZIPCO & PF3D7_1022300 & $\begin{array}{l}\text { Essential in } \\
\text { liver stage }\end{array}$ & $\begin{array}{l}\text { Periphery of } \\
\text { parasites (Sahu } \\
\text { et al., 2014) }\end{array}$ & TGME49_225530 & -2.94 & - \\
\hline & DMT1 & PF3D7_0523800 & Essential & - & TGME49_267270 & 0.49 & - \\
\hline & mitoferrin & PF3D7_0905200 & Essential & - & TGME49_277090 & -3.05 & mitochondrial \\
\hline
\end{tabular}
considered dispensable, LOPIT localization data from (Barylyuk et al., 2020). 
Zinc is an essential cofactor for a large number of proteins including DNA binding domains, metalloproteases and ribosomal subunits (Cassandri et al., 2017; Eide, 2006). In the Apicomplexa, many zinc-binding proteins are conserved, and-although the majority have not yet been functionally characterised-several are important 194 throughout the parasites' life cycles. For example, zinc finger proteins have been shown to regulate life cycle transitions, and secreted zinc-bound metalloproteases are required for the parasite's lytic cycle (Gopalakrishnan et al., 2017; Hajagos et al., 2012; Semenovskaya et al., 2020; Tanveer et al., 2013). In Plasmodium it has been shown that parasites accumulate large amounts of zinc (approximately $400 \%$ of that found within normal erythrocytes) and that inhibition of zinc acquisition prevents parasite replication (Marvin et al., 2012). A similar, although less dramatic, increase in zinc levels in the host cell is seen upon $T$. gondii infection (Al-Sandaqchi et al., 2018), suggesting that manipulation of host cell zinc levels is common between the Apicomplexa. Within Plasmodium, much of this zinc appears to be weakly bound to chaperones within the mitochondrion of the parasite (Marvin et al., 2012). The purpose of this is not clear, but may have a role in mitochondrial respiration, as was demonstrated in the intracellular parasitic protozoa Leishmania donovani (Kumari et al., 2017). Despite the accumulation of zinc within infected cells, zinc deficiency or supplementation, either in rodents or in humans, does not appear to alter pathogenesis of Cryptosporidium or Plasmodium respectively (Hamaguchi et al., 2006; Müller et al., 2001; Veenemans et al., 2011). It is possible that zinc accumulation does not change the availability of zinc to the parasite. Zinc sequestration and relocalization are important facets of nutritional immunity (Vignesh and Deepe, 2016), and it is likely that these successful pathogens have developed highly effective mechanisms for zinc uptake in the face of host

212 A number of transporters required for zinc uptake and mobilisation in model organisms have been identified 213 (Eide, 2006). Within mammalian cells, zinc is transported into the cell by a several high affinity transporters. 214 Proteins of the ZIP (Zrt-, Irt-like Protein) family move zinc into the cytoplasm while cation diffusion 215 facilitator (CDF) proteins move zinc from the cytoplasm to the lumen of membrane-bound compartments. 216 Within a cell, almost all exchangeable zinc is bound to chaperones which move it to where it is required, e.g. 217 into the ER and Golgi where it can be inserted into newly synthesized proteins. Excess zinc is toxic through 218 a number of mechanisms including by displacing metal cofactors, disrupting protein folding and inducing 219 apoptosis, and so cytosolic levels of exchangeable zinc are maintained at a very low level (Maret, 2009; Maret and Krężel, 2007; Plum et al., 2010).

In mammalian and bacterial cells, zinc is removed from the cytosol by zinc efflux transporters, however, in a similar manner to iron, yeast stores zinc within a vacuole (Eide, 2006). Recently the first apicomplexan zinc transporter, named ZnT, was characterised in T. gondii (Fig. 1 and Table 2). ZnT is localised to dynamic, vesicular compartments (Chasen et al., 2019), which, in concert with X-ray microanalysis, suggest zinc is 
stored within acidocalcisomes (Luo et al., 2001; Rohloff et al., 2011). Confirming its suspected role, ZnT was

227 found to complement a yeast zinc storage mutant and to be essential for maintaining zinc tolerance within 228 T. gondii (Chasen et al., 2019). Interestingly, although the ZnT transporter is conserved in Plasmodium and 229 highly expressed in late blood stages, it is not required for parasite replication (Aurrecoechea et al., 2009). 230 Instead, Znt was required for male gamete exflagellation and ookinete formation (Kenthirapalan et al., 231 2016). ZIP1, a predicted Zn or Fe permease, was shown to have a role in blood stage replication, however 232 was also required for gamete production (Kenthirapalan et al., 2016; Sayers et al., 2018). A possible T. gondii 233 ZIP1 homolog (TGME49_261720) was predicted to localise to the plasma membrane and is likely essential in 234 vitro. These results suggest that zinc has increased importance in the differentiation of Plasmodium to sexual 235 stages, perhaps the rational for the accumulation in the asexual bloodstream form.

237 The mechanism of zinc acquisition remains an open question. Although Plasmodium encodes only two ZIP238 domain containing proteins, T. gondii encodes four (Table 2) which could perform this role, however these 239 have not yet been characterised. Further, due to its numerous roles in essential proteins, zinc is likely to be 240 required in other organelles including the mitochondrion, ER and Golgi (Fig. 1). There is currently no direct 241 evidence for a zinc requirement in the apicoplast, although it is possible as the potential zinc transporter ZIP1 242 contains an apicoplast targeting sequence in Plasmodium (Sayers et al., 2018). Mammalian and yeast cells 243 encode transporters to move zinc between organelles (Bafaro et al., 2017; Eide, 2006), however functional 244 homologs of these have not yet been identified in apicomplexan parasites. Given the lack of homologues to 245 known zinc transporters, this may suggest that the Apicomplexa utilize divergent mechanisms for zinc uptake 246 and transport within the cell. This, combined with the importance of zinc to parasite biology, makes parasite 247 zinc pathways an attractive target for intervention.

\begin{tabular}{|c|c|c|c|c|c|c|c|}
\hline \multicolumn{5}{|c|}{ Plasmodium } & \multicolumn{3}{|l|}{ T. gondii } \\
\hline Type & $\begin{array}{l}\text { Gene } \\
\text { name }\end{array}$ & Pf ID & Phenotype & Localization & $\mathrm{Tg}$ ID & $\begin{array}{l}\text { Phenotype } \\
\text { score }\end{array}$ & $\begin{array}{l}\text { Localisation } \\
\text { prediction }\end{array}$ \\
\hline Transporter & $\begin{array}{l}\mathrm{ZnT} \\
/ \mathrm{CDF}\end{array}$ & PF3D7_0715900 & Dispensable & - & TGME49_251630 & -3.06 & $\begin{array}{l}\text { Plant-like vacuole } \\
\text { Vesicular (Chasen } \\
\text { et al., 2019) }\end{array}$ \\
\hline \multirow[t]{3}{*}{$\begin{array}{l}\text { Zrt-, Irt- } \\
\text { like }\end{array}$} & ZIP1 & PF3D7_0609100 & Essential & - & TGME49_261720 & -4.31 & Plasma membrane \\
\hline & & & & & TGME49_254080 & 1.41 & $\begin{array}{l}\text { Secretory } \\
\text { organelles, } \\
\text { rhoptries }\end{array}$ \\
\hline & & & & & TGME49_260300 & -1.4 & - \\
\hline
\end{tabular}


Table 2. Transporters expected to be involved in zinc transport in apicomplexan parasites. $P$. falciparum phenotype data from (Zhang et al., 2018). T. gondii phenotype data from (Sidik et al., 2016), values $>\sim-1.5$ are considered dispensable, localization prediction data from (Barylyuk et al., 252 2020).

\section{Capture and cloistering of Copper}

Although only required in very small amounts, copper plays an key role in cellular processes. It acts as a cofactor in a number of essential enzymes including $\mathrm{Zn} / \mathrm{Cu}$ superoxide dismutase (Cu/Zn-SOD), cytochrome $c$ oxidase and other enzymes involved in diverse pathways such as pigmentation and peptide processing (Balamurugan and Schaffner, 2006). Of these, cytochrome $c$ oxidase is conserved in apicomplexans and is essential for energy production. Plasmodium-infected erythrocytes accumulate copper (Marvin et al., 2012). The reason for this is not known, but is possibly related to parasite cytochrome $c$ production. However, this accumulation is likely important as copper chelation has been shown to block Plasmodium replication in erythrocytes (Asahi et al., 2014; Rasoloson et al., 2004). Blocking replication this effect appears more pronounced when using $\mathrm{Cu}^{+}$, rather than $\mathrm{Cu}^{2+}$, chelators (Asahi et al., 2014), suggesting that $\mathrm{Cu}^{+}$is the form required by the parasite. Copper is also required by Plasmodium in the mosquito definitive host (MayaMaldonado et al., 2021) although it was not clear if the various Plasmodium life cycle stages in the mosquito have different copper requirements. No studies have yet looked specifically at the copper requirements of $T$. gondii or Cryptosporidium. However, although copper is likely to be required by $T$. gondii, several Cryptosporidium species have lost cytochrome $c$ oxidase, replacing it with alternative oxidase (AOX), and so may not require for copper (Liu et al., 2016). However, even in the absence of cytochrome $c$ oxidase, Cryptosporidium spp. have maintained a likely homolog of CTR and a Cu-binding P-ATPase (see below) (LaGier et al., 2001), providing circumstantial evidence for a requirement for copper beyond energy production in these cells. The effects of Plasmodium infection on host cell copper are unclear, previously it was shown copper levels either decrease (Rasoloson et al., 2004) or increase (Marvin et al., 2012) in trophozoite-infected red blood cells. T. gondii infection appeared to increase the copper content (AlSandaqchi et al., 2018). Within cells, very little exchangeable copper is present with the large majority bound tightly to host cell proteins making copper acquisition a challenge for intracellular pathogens (Li et al., 2019).

In mammalian and yeast cells, copper uptake occurs through a high affinity copper transporter CTR1, copper is then bound to acceptors such as GSH and transported to chaperones (Kaplan and Maryon, 2016). Copper efflux occurs though Golgi-localised P-ATPases which traffic to the plasma membrane upon copper overload, removing copper from the cell (Kaplan and Maryon, 2016). Two putative copper transporters have been investigated in Plasmodium (Table 3), a copper transporter CTR1 and a Cu P-ATPase named CuTP (Choveaux et al., 2012; Kenthirapalan et al., 2014; Rasoloson et al., 2004). PfCTR1 was localised to the erythrocyte membrane and is predicted to be essential during asexual replication in Plasmodium (Choveaux et al., 2012). 
In $T$. gondii, a CTR1 homologue is likely essential and is predicted to localise to the Golgi, although no characterisation has yet been carried out. The P-ATPase CuTP is conserved in Cryptosporidium where it was shown to specifically bind copper (LaGier et al., 2001). Work in both P. berghei and T. gondii showed that $\mathrm{CuTP}$ was localised to vesicular structures at all life cycle stages, and showed some overlap with the vacuolar marker VP1 in T. gondii, suggesting a role of CuTP in copper storage (Kenthirapalan et al., 2014). CuTP was not shown to be essential for blood stage growth or gametocyte production in P. berghei, however is essential in gametocyte fertility (Kenthirapalan et al., 2014), suggesting that this life cycle stage has an altered requirement for copper. The Apicomplexa also encode a homolog of the mitochondrial phosphate/copper transporter PIC2 (Zhu et al., 2021) which is predicted to be essential and mitochondrially-localised in $T$.

There are a number of fairly well-defined pathways in plants, fungi and mammalian cells to sense and respond to changes in copper levels (Blaby-Haas and Merchant, 2012, Ehrensberger and Bird, 2011) however no homologues of known response elements can be found in the Apicomplexa. It is possible that as obligate intracellular parasites, they no longer need to respond to changes in copper levels as their hosts will contain sufficient copper for replication. Alternatively, the parasites can sense and respond, however the components are divergent from known pathways and so have not yet been identified.

In summary, the role of copper in apicomplexan development deserves further investigation. There is evidence that maintenance of copper homeostasis is required by the parasites, and some of the genes involved

304 in this process have been identified and initially characterised (Table 3 and Fig.1). However, the topic merits 305 systematic investigation as copper homeostasis has been shown to be vital in the virulence of a number of 306 pathogens (Blaby-Haas and Merchant, 2012; Ehrensberger and Bird, 2011).

\begin{tabular}{|c|c|c|c|c|c|c|c|}
\hline \multicolumn{5}{|c|}{ Plasmodium } & \multicolumn{3}{|l|}{$T$. gondii } \\
\hline Type & $\begin{array}{l}\text { Gene } \\
\text { name }\end{array}$ & Pf ID & Phenotype & Localisation & $\mathrm{Tg}$ ID & $\begin{array}{l}\text { Phenotype } \\
\text { score }\end{array}$ & $\begin{array}{l}\text { Localisation } \\
\text { prediction }\end{array}$ \\
\hline Transporter & CTR1 & PF3D7_1439000 & Essential & $\begin{array}{l}\text { Translocates from } \\
\text { the erythrocyte } \\
\text { plasma membrane in } \\
\text { early ring stage to a } \\
\text { parasite membrane } \\
\text { as the parasites } \\
\text { developed to } \\
\text { schizonts (Choveaux } \\
\text { et al., 2012) }\end{array}$ & TGME49_262710 & -2.62 & Golgi \\
\hline Channel & CTR2 & PF3D7_1421900 & Essential & - & TGME49_249200 & 2.31 & - \\
\hline
\end{tabular}




\begin{tabular}{|c|c|c|c|c|c|c|c|}
\hline ATPase & CuTP & PF3D7_0904900 & Dispensable & $\begin{array}{l}\text { Expressed in all } \\
\text { Plasmodium life } \\
\text { cycle stages. } \\
\text { Localizes to vesicle- } \\
\text { like structures } \\
\text { (Kenthirapalan et al., } \\
2014)\end{array}$ & TGME49_201150 & -1.57 & $\begin{array}{l}\text { Endomembrane } \\
\text { vesicles, co- } \\
\text { localises with the } \\
\text { VAC } \\
\text { (Kenthirapalan et } \\
\text { al., 2016) }\end{array}$ \\
\hline Metallochaperone & Cox17 & PF3D7_1025600 & $?$ & $\begin{array}{l}\text { Cytoplasmic } \\
\text { localisation in } \\
\text { asexuals (Choveaux } \\
\text { et al., 2015) }\end{array}$ & TGME49_240550 & -2.7 & Mitochondrial \\
\hline $\begin{array}{l}\text { Mitochondrial } \\
\text { copper/phosphate } \\
\text { transporter }\end{array}$ & PIC2 & PF3D7_1202200 & Dispensable & - & TGME49_278990 & -2.7 & Mitochondrial \\
\hline
\end{tabular}

309 Table 3. Genes involved in copper homeostasis in apicomplexan parasites. P. falciparum phenotype data from 310 (Zhang et al., 2018). T. gondii phenotype data from (Sidik et al., 2016), values $>\sim-1.5$ are considered 311 dispensable, LOPIT data from (Barylyuk et al., 2020).

\section{Summary}

314 Despite the importance of Apicomplexa, both clinically and in veterinary practice, the study of the uptake,

315 use and storage of essential metals lags behind work done in other organisms. Transporter characterisation 316 has improved in recent years, and the identification of several metal transporters has underlined the 317 importance of metals to the parasites, however a number of predicted transporters remain unknown. Further, 318 the role of transcriptional and post-transcriptional regulation in metal uptake and storage has not been 319 addressed, despite these processes being tightly controlled in other systems. This limits our ability to 320 understand how these pathogens interact with their hosts, and how they respond to and overcome host 321 nutritional immunity.

323 As highly divergent parasitic eukaryotes which often cycle between mammalian and insect hosts, there may 324 well be important biological differences in how metals are handled which could be exploited therapeutically. 325 One interesting area for future investigation is the apicoplast, which depends on iron import (Gisselberg et 326 al., 2013), but has no identified iron transporters. By identifying the strategies employed to transport metals around the cell we have the opportunity to learn more about how the common problem of metal acquisition and storage has been addressed across the broader tree of life. 
331 Figure 1. Summary of expected iron, zinc and copper transporters in apicomplexan parasites

333 A schematic showing the major organelles of $T$. gondii as a model apicomplexan and the expected localisation 334 of transporters involved in metal transport throughout the cell. As the parasitophorous vacuolar membrane 335 (PVM) is permeable, it is not known if transporters would be required to move metals into the PV space. 336 Apicomplexa appear to be able to endocytose material from the host which may provide a source of metal337 containing proteins Iron is required in the mitochondria and apicoplast (see text for details) and may be 338 required in the ER and is likely stored in a vacuolar compartment (VAC). A single apicoplast-localised 339 transporter has been indicated, but it is likely that more than one would be required to cross the four 340 membranes of the apicoplast. Zinc is likely required in the mitochondria, ER and Golgi and the zinc 341 transporter $\mathrm{ZnT}$ has been localised to multiple compartments, potentially acidocalcisomes and the vacuolar 342 compartment. Copper is required in the mitochondria and copper transporters have been putatively localised 343 to the VAC and Golgi. Transparent transporters (marked with ?) show the likely location of transporters that 344 have not yet been identified. Iron/iron transporters- red, copper/copper transporters-blue and zinc/zinc 345 transporters - grey.

\section{Funding information}

C.R.H and M.A.S are funded by a Sir Henry Dale fellowship to C.R.H (213455/Z/18/Z) from the Wellcome University of Glasgow.

\section{Conflict of Interest}

The authors declare that there are no conflicts of interest

\section{References}

Alén, C., Sonenshein, A.L., 1999. Bacillus subtilis aconitase is an RNA-binding protein. Proc Natl Acad 
Almeida, M.P.O., Ferro, E.A.V., Briceño, M.P.P., Oliveira, M.C., Barbosa, B.F., Silva, N.M., 2019.

Susceptibility of human villous (BeWo) and extravillous (HTR-8/SVneo) trophoblast cells to Toxoplasma gondii infection is modulated by intracellular iron availability. Parasitol Res 118, 1559-1572. https://doi.org/10.1007/s00436-019-06257-2

Al-Sandaqchi, A.T., Brignell, C., Collingwood, J.F., Geraki, K., Mirkes, E.M., Kong, K., Castellanos, M., May, S.T., Stevenson, C.W., Elsheikha, H.M., 2018. Metallome of cerebrovascular endothelial cells infected with Toxoplasma gondii using $\mu-\mathrm{XRF}$ imaging and inductively coupled plasma mass spectrometry. Metallomics 10, 1401-1414. https://doi.org/10.1039/c8mt00136g

Asahi, H., Tolba, M.E.M., Tanabe, M., Sugano, S., Abe, K., Kawamoto, F., 2014. Perturbation of copper homeostasis is instrumental in early developmental arrest of intraerythrocytic Plasmodium falciparum. BMC Microbiol 14, 167. https://doi.org/10.1186/1471-2180-14-167

Aurrecoechea, C., Brestelli, J., Brunk, B.P., Dommer, J., Fischer, S., Gajria, B., Gao, X., Gingle, A., Grant,

V., Pennington, C., Pinney, D.F., Roos, D.S., Ross, C., Stoeckert, C.J., Treatman, C., Wang, H., 2009. PlasmoDB: a functional genomic database for malaria parasites. Nucleic Acids Res 37, D539-543. https://doi.org/10.1093/nar/gkn814

Bafaro, E., Liu, Y., Xu, Y., Dempski, R.E., 2017. The emerging role of zinc transporters in cellular homeostasis and cancer. Signal Transduct Target Ther 2, 17029. https://doi.org/10.1038/sigtrans.2017.29

Balamurugan, K., Schaffner, W., 2006. Copper homeostasis in eukaryotes: Teetering on a tightrope.

Biochimica et Biophysica Acta (BBA) - Molecular Cell Research, Cell Biology of Metals 1763, 737-746. https://doi.org/10.1016/j.bbamcr.2006.05.001

Ballesteros, C., Geary, J.F., Mackenzie, C.D., Geary, T.G., 2018. Characterization of Divalent Metal

Transporter 1 (DMT1) in Brugia malayi suggests an intestinal-associated pathway for iron absorption. Int J Parasitol Drugs Drug Resist 8, 341-349. https://doi.org/10.1016/j.ijpddr.2018.06.003

Barylyuk, K., Koreny, L., Ke, H., Butterworth, S., Crook, O.M., Lassadi, I., Gupta, V., Tromer, E.,

Mourier, T., Stevens, T.J., Breckels, L.M., Pain, A., Lilley, K.S., Waller, R.F., 2020. A Comprehensive Subcellular Atlas of the Toxoplasma Proteome via hyperLOPIT Provides Spatial Context for Protein Functions. Cell Host \& Microbe 28, 752-766.e9. https://doi.org/10.1016/j.chom.2020.09.011

Bergmann, A., Floyd, K., Key, M., Dameron, C., Rees, K.C., Thornton, L.B., Whitehead, D.C., Hamza, I., Dou, Z., 2020. Toxoplasma gondii requires its plant-like heme biosynthesis pathway for infection. PLOS Pathogens 16, e1008499. https://doi.org/10.1371/journal.ppat.1008499

Bunnag, D., Poltera, A.A., Viravan, C., Looareesuwan, S., Harinasuta, K.T., Schindléry, C., 1992. Plasmodicidal effect of desferrioxamine B in human vivax or falciparum malaria from Thailand. Acta Trop 52, 59-67. https://doi.org/10.1016/0001-706x(92)90007-k 
Cassandri, M., Smirnov, A., Novelli, F., Pitolli, C., Agostini, M., Malewicz, M., Melino, G., Raschellà, G., 2017. Zinc-finger proteins in health and disease. Cell Death Discovery 3, 1-12. https://doi.org/10.1038/cddiscovery.2017.71

Charan, M., Choudhary, H.H., Singh, N., Sadik, M., Siddiqi, M.I., Mishra, S., Habib, S., 2017. [Fe-S] cluster assembly in the apicoplast and its indispensability in mosquito stages of the malaria parasite. The FEBS Journal 284, 2629-2648. https://doi.org/10.1111/febs.14159

Chasen, N.M., Stasic, A.J., Asady, B., Coppens, I., Moreno, S.N.J., 2019. The Vacuolar Zinc Transporter TgZnT Protects Toxoplasma gondii from Zinc Toxicity. mSphere 4. https://doi.org/10.1128/mSphere.0008619

Choveaux, D.L., Krause, R.G.E., Przyborski, J.M., Goldring, J.P.D., 2015. Identification and initial 404 characterisation of a Plasmodium falciparum Cox17 copper metallochaperone. Experimental Parasitology 148, 30-39. https://doi.org/10.1016/j.exppara.2014.11.001

Choveaux, D.L., Przyborski, J.M., Goldring, J.D., 2012. A Plasmodium falciparum copper-binding membrane protein with copper transport motifs. Malar J 11, 397. https://doi.org/10.1186/1475-2875-11-397

Clark, M.A., Goheen, M.M., Fulford, A., Prentice, A.M., Elnagheeb, M.A., Patel, J., Fisher, N., Taylor, S.M., Kasthuri, R.S., Cerami, C., 2014. Host iron status and iron supplementation mediate susceptibility to erythrocytic stage Plasmodium falciparum. Nat Commun 5, 4446. https://doi.org/10.1038/ncomms5446

Dellibovi-Ragheb, T.A., Gisselberg, J.E., Prigge, S.T., 2013. Parasites FeS Up: Iron-Sulfur Cluster Biogenesis in Eukaryotic Pathogens. PLOS

Pathogens

9, $\quad$ e1003227. https://doi.org/10.1371/journal.ppat.1003227

Dimier, I.H., Bout, D.T., 1998. Interferon-gamma-activated primary enterocytes inhibit Toxoplasma gondii replication: a role for intracellular iron. Immunology 94, 488-495. https://doi.org/10.1046/j.13652567.1998.00553.x

Dixon, S.J., Stockwell, B.R., 2014. The role of iron and reactive oxygen species in cell death. Nat Chem Biol 10, 9-17. https://doi.org/10.1038/nchembio.1416

Dou, Z., McGovern, O.L., Cristina, M.D., Carruthers, V.B., 2014. Toxoplasma gondii Ingests and Digests Host Cytosolic Proteins. mBio 5. https://doi.org/10.1128/mBio.01188-14

Eide, D.J., 2006. Zinc transporters and the cellular trafficking of zinc. Biochimica et Biophysica Acta (BBA) - Molecular Cell Research, Cell Biology of Metals 1763, 711-722. https://doi.org/10.1016/j.bbamcr.2006.03.005

Ferrer, P., Tripathi, A.K., Clark, M.A., Hand, C.C., Rienhoff, H.Y., Sullivan, D.J., 2012. Antimalarial iron chelator, FBS0701, shows asexual and gametocyte Plasmodium falciparum activity and single oral dose cure in a murine malaria model. PLoS One 7, e37171. https://doi.org/10.1371/journal.pone.0037171 

permeable channel in the vacuolar membrane of Plasmodium and is essential for protein export via PTEX. Nat Microbiol 3, 1090-1098. https://doi.org/10.1038/s41564-018-0222-7

Gisselberg, J.E., Dellibovi-Ragheb, T.A., Matthews, K.A., Bosch, G., Prigge, S.T., 2013. The Suf Iron-

Sulfur Cluster Synthesis Pathway Is Required for Apicoplast Maintenance in Malaria Parasites. PLOS Pathogens 9, e1003655. https://doi.org/10.1371/journal.ppat.1003655

Gold, D.A., Kaplan, A.D., Lis, A., Bett, G.C., Rosowski, E.E., Cirelli, K.M., Bougdour, A., Sidik, S.M., Beck, J.R., Lourido, S., Egea, P.F., Bradley, P.J., Hakimi, M.-A., Rasmusson, R.L., Saeij, J.P., 2015. The Toxoplasma dense granule proteins GRA17 and GRA23 mediate the movement of small molecules between the host and the parasitophorou vacuole. Cell Host Microbe 17, 7, $\quad 642-652$. https://doi.org/10.1016/j.chom.2015.04.003

Goma, J., Rénia, L., Miltgen, F., Mazier, D., 1996. Iron overload increases hepatic development of Plasmodium yoelii in mice. Parasitology 112 ( Pt 2), 165-168. https://doi.org/10.1017/s0031182000084729

Gopalakrishnan, A.M., Aly, A.S.I., Aravind, L., Kumar, N., 2017. Multifunctional Involvement of a C2H2 Zinc Finger Protein (PbZfp) in Malaria Transmission, Histone Modification, and Susceptibility to DNA Damage Response. mBio 8. https://doi.org/10.1128/mBio.01298-17

Gordeuk, V., Thuma, P., Brittenham, G., McLaren, C., Parry, D., Backenstose, A., Biemba, G., Msiska, R., Holmes, L., McKinley, E., 1992. Effect of iron chelation therapy on recovery from deep coma in children with cerebral malaria. N Engl J Med 327, 1473-1477. https://doi.org/10.1056/NEJM199211193272101

Hajagos, B.E., Turetzky, J.M., Peng, E.D., Cheng, S.J., Ryan, C.M., Souda, P., Whitelegge, J.P., Lebrun, M., Dubremetz, J.-F., Bradley, P.J., 2012. Molecular dissection of novel trafficking and processing of the Toxoplasma gondii rhoptry metalloprotease toxolysin-1. Traffic 13, 292-304. https://doi.org/10.1111/j.16000854.2011.01308.x

Hamaguchi, K. (Nippon V. and L.S.U., Takahashi, J., Suzuki, C., Honma, H., Nakai, Y., Imai, S., 2006. Infectivity of Cryptosporidium muris and C. parvum to zinc deficient rats and mice. Bulletin of the Nippon Veterinary and Life Science University (Japan).

Harding, C.R., Frischknecht, F., 2020. The Riveting Cellular Structures of Apicomplexan Parasites. Trends in Parasitology 36, 979-991. https://doi.org/10.1016/j.pt.2020.09.001

Hentze, M.W., Rouault, T.A., Caughman, S.W., Dancis, A., Harford, J.B., Klausner, R.D., 1987. A cisacting element is necessary and sufficient for translational regulation of human ferritin expression in response to iron. Proc Natl Acad Sci U S A 84, 6730-6734. https://doi.org/10.1073/pnas.84.19.6730

Hodges, M., Yikilmaz, E., Patterson, G., Kasvosve, I., Rouault, T.A., Gordeuk, V.R., Loyevsky, M., 2005. An iron regulatory-like protein expressed in Plasmodium falciparum displays aconitase activity. Mol Biochem Parasitol 143, 29-38. https://doi.org/10.1016/j.molbiopara.2005.05.004 
Jacot, D., Waller, R.F., Soldati-Favre, D., MacPherson, D.A., MacRae, J.I., 2016. Apicomplexan Energy Metabolism: Carbon Source Promiscuity and the Quiescence Hyperbole. Trends Parasitol 32, 56-70. https://doi.org/10.1016/j.pt.2015.09.001

Kaplan, J.H., Maryon, E.B., 2016. How Mammalian Cells Acquire Copper: An Essential but Potentially Toxic Metal. Biophysical Journal 110, 7-13. https://doi.org/10.1016/j.bpj.2015.11.025

Kato, T., Kumazaki, K., Wada, M., Taniguchi, R., Nakane, T., Yamashita, K., Hirata, K., Ishitani, R., Ito, K., Nishizawa, T., Nureki, O., 2019. Crystal structure of plant vacuolar iron transporter VIT1. Nature Plants 5, 308-315. https://doi.org/10.1038/s41477-019-0367-2

Kenthirapalan, S., Waters, A.P., Matuschewski, K., Kooij, T.W.A., 2016. Functional profiles of orphan membrane transporters in the life cycle of the malaria parasite. Nature Communications 7, 10519. https://doi.org/10.1038/ncomms10519

Kenthirapalan, S., Waters, A.P., Matuschewski, K., Kooij, T.W.A., 2014. Copper-transporting ATPase is important for malaria parasite fertility. Molecular Microbiology 91, 315-325. https://doi.org/10.1111/mmi.12461

Kim, S.A., Punshon, T., Lanzirotti, A., Li, L., Alonso, J.M., Ecker, J.R., Kaplan, J., Guerinot, M.L., 2006. Localization of iron in Arabidopsis seed requires the vacuolar membrane transporter VIT1. Science 314, 1295-1298. https://doi.org/10.1126/science.1132563

Kloehn, J., Harding, C.R., Soldati-Favre, D., 2020. Supply and demand-heme synthesis, salvage and utilization by Apicomplexa. The FEBS Journal n/a. https://doi.org/10.1111/febs.15445 A cytosolic protein binds to structural elements within the iron regulatory region of the transferrin receptor mRNA. Proc Natl Acad Sci U S A 86, 3574-3578. https://doi.org/10.1073/pnas.86.10.3574

Labarbuta, P., Duckett, K., Botting, C.H., Chahrour, O., Malone, J., Dalton, J.P., Law, C.J., 2017. Recombinant vacuolar iron transporter family homologue PfVIT from human malaria-causing Plasmodium falciparum is a Fe 2+ /H + exchanger. Scientific Reports 7, 42850. https://doi.org/10.1038/srep42850

LaGier, M.J., Tachezy, J., Stejskal, F., Kutisova, K., Keithly, J.S., 2003. Mitochondrial-type iron-sulfur cluster biosynthesis genes (IscS and IscU) in the apicomplexan Cryptosporidium parvum. Microbiology (Reading) 149, 3519-3530. https://doi.org/10.1099/mic.0.26365-0

Li, C., Li, Y., Ding, C., 2019. The Role of Copper Homeostasis at the Host-Pathogen Axis: From Bacteria to Fungi. Int J Mol Sci 20. https://doi.org/10.3390/ijms20010175

Li, L., Chen, O.S., McVey Ward, D., Kaplan, J., 2001. CCC1 is a transporter that mediates vacuolar iron storage in yeast. J Biol Chem 276, 29515-29519. https://doi.org/10.1074/jbc.M103944200

Liu, J., Istvan, E.S., Gluzman, I.Y., Gross, J., Goldberg, D.E., 2006. Plasmodium falciparum ensures its amino acid supply with multiple acquisition pathways and redundant proteolytic enzyme systems. PNAS 103, 8840-8845. 
Liu, S., Roellig, D.M., Guo, Y., Li, N., Frace, M.A., Tang, K., Zhang, L., Feng, Y., Xiao, L., 2016. Evolution of mitosome metabolism and invasion-related proteins in Cryptosporidium. BMC Genomics 17, 1006. https://doi.org/10.1186/s12864-016-3343-5

Loyevsky, M., LaVaute, T., Allerson, C.R., Stearman, R., Kassim, O.O., Cooperman, S., Gordeuk, V.R., Rouault, T.A., 2001. An IRP-like protein from Plasmodium falciparum binds to a mammalian iron-responsive element. Blood 98, 2555-2562. https://doi.org/10.1182/blood.V98.8.2555

Loyevsky, M., Mompoint, F., Yikilmaz, E., Altschul, S.F., Madden, T., Wootton, J.C., Kurantsin-Mills, J., Kassim, O.O., Gordeuk, V.R., Rouault, T.A., 2003. Expression of a recombinant IRP-like Plasmodium falciparum protein that specifically binds putative plasmodial IREs. Mol Biochem Parasitol 126, 231-238. https://doi.org/10.1016/s0166-6851(02)00278-5

Luo, S., Vieira, M., Graves, J., Zhong, L., Moreno, S.N., 2001. A plasma membrane-type Ca(2+)-ATPase co-localizes with a vacuolar $\mathrm{H}(+)$-pyrophosphatase to acidocalcisomes of Toxoplasma gondii. EMBO J 20, 5564. https://doi.org/10.1093/emboj/20.1.55

Mahmoud, M.S., 1999. Effect of deferoxamine alone and combined with pyrimethamine on acute toxoplasmosis in mice. J Egypt Soc Parasitol 29, 791-803.

Maret, W., 2009. Molecular aspects of human cellular zinc homeostasis: redox control of zinc potentials and zinc signals. Biometals 22, 149-157. https://doi.org/10.1007/s10534-008-9186-z

Maret, W., Krężel, A., 2007. Cellular Zinc and Redox Buffering Capacity of Metallothionein/Thionein in Health and Disease. Mol Med 13, 371-375. https://doi.org/10.2119/2007-00036.Maret

Marondedze, C., Thomas, L., Serrano, N.L., Lilley, K.S., Gehring, C., 2016. The RNA-binding protein repertoire of Arabidopsis thaliana. Sci Rep 6, 29766. https://doi.org/10.1038/srep29766

Marvin, R.G., Wolford, J.L., Kidd, M.J., Murphy, S., Ward, J., Que, E.L., Mayer, M.L., Penner-Hahn, J.E., Haldar, K., O'Halloran, T.V., 2012. Fluxes in 'Free' and Total Zinc are Essential for Progression of Intraerythrocytic Stages of Plasmodium falciparum. Chem Biol 19, 731-741. https://doi.org/10.1016/j.chembiol.2012.04.013

Maya-Maldonado, K., Cardoso-Jaime, V., González-Olvera, G., Osorio, B., Recio-Tótoro, B., ManriqueSaide, P., Rodríguez-Sánchez, I.P., Lanz-Mendoza, H., Missirlis, F., Hernández-Hernández, F. de la C., 2021. Mosquito metallomics reveal copper and iron as critical factors for Plasmodium infection. PLoS Negl Trop Dis 15, e0009509. https://doi.org/10.1371/journal.pntd.0009509

McGovern, O.L., Rivera-Cuevas, Y., Carruthers, V.B., 2021. Emerging Mechanisms of Endocytosis in Toxoplasma gondii. Life (Basel) 11, 84. https://doi.org/10.3390/life11020084

Mengist, H.M., Taye, B., Tsegaye, A., 2015. Intestinal Parasitosis in Relation to CD4+T Cells Levels and Anemia among HAART Initiated and HAART Naive Pediatric HIV Patients in a Model ART Center in Addis Ababa, Ethiopia. PLoS One 10, e0117715. https://doi.org/10.1371/journal.pone.0117715 
Miller, C.N., Jossé, L., Tsaousis, A.D., 2018. Localization of Fe-S Biosynthesis Machinery in 531 Cryptosporidium parvum Mitosome. J Eukaryot Microbiol 65, 913-922. https://doi.org/10.1111/jeu.12663

Müller, O., Becher, H., van Zweeden, A.B., Ye, Y., Diallo, D.A., Konate, A.T., Gbangou, A., Kouyate, B., Garenne, M., 2001. Effect of zinc supplementation on malaria and other causes of morbidity in west African children: randomised double blind placebo controlled trial. BMJ 322, 1567.

Muriuki, J.M., Mentzer, A.J., Kimita, W., Ndungu, F.M., Macharia, A.W., Webb, E.L., Lule, S.A., Morovat, A., Hill, A.V.S., Bejon, P., Elliott, A.M., Williams, T.N., Atkinson, S.H., 2019. Iron Status and

Associated Malaria Risk Among African Children. Clin Infect Dis 68, 1807-1814. https://doi.org/10.1093/cid/ciy791

Oliveira, M.C., Coutinho, L.B., Almeida, M.P.O., Briceño, M.P., Araujo, E.C.B., Silva, N.M., 2020. The Availability of Iron Is Involved in the Murine Experimental Toxoplasma gondii Infection Outcome. Microorganisms 8, E560. https://doi.org/10.3390/microorganisms8040560

Plum, L.M., Rink, L., Haase, H., 2010. The Essential Toxin: Impact of Zinc on Human Health. Int J Environ Res Public Health 7, 1342-1365. https://doi.org/10.3390/ijerph7041342

Pollack, S., Fleming, J., 1984. Plasmodium falciparum takes up iron from transferrin. Br J Haematol 58, 289-293. https://doi.org/10.1111/j.1365-2141.1984.tb06087.x

Pollack, S., Rossan, R.N., Davidson, D.E., Escajadillo, A., 1987. Desferrioxamine suppresses Plasmodium falciparum in Aotus monkeys. Proc Soc Exp Biol Med 184, 162-164. https://doi.org/10.3181/00379727-18442461

Portugal, S., Carret, C., Recker, M., Armitage, A.E., Gonçalves, L.A., Epiphanio, S., Sullivan, D., Roy, C., Newbold, C.I., Drakesmith, H., Mota, M.M., 2011. Host-mediated regulation of superinfection in malaria. Nature Medicine 17, 732-737. https://doi.org/10.1038/nm.2368

Rasoloson, D., Shi, L., Chong, C.R., Kafsack, B.F., Sullivan, D.J., 2004. Copper pathways in Plasmodium falciparum infected erythrocytes indicate an efflux role for the copper P-ATPase. Biochem J 381, 803-811. https://doi.org/10.1042/BJ20040335

Rodriguez, M.H., Jungery, M., 1986. A protein on Plasmodium falciparum-infected erythrocytes functions as a transferrin receptor. Nature 324, 388-391. https://doi.org/10.1038/324388a0

Rohloff, P., Miranda, K., Rodrigues, J.C.F., Fang, J., Galizzi, M., Plattner, H., Hentschel, J., Moreno, S.N.J., 2011. Calcium Uptake and Proton Transport by Acidocalcisomes of Toxoplasma gondii. PLOS ONE 6, e18390. https://doi.org/10.1371/journal.pone.0018390

Roschzttardtz, H., Conéjéro, G., Curie, C., Mari, S., 2009. Identification of the Endodermal Vacuole as the Iron Storage Compartment in the Arabidopsis Embryo. Plant Physiology 151, 1329-1338. https://doi.org/10.1104/pp.109.144444 
Sahu, T., Boisson, B., Lacroix, C., Bischoff, E., Richier, Q., Formaglio, P., Thiberge, S., Dobrescu, I.,

Ménard, R., Baldacci, P., 2014. ZIPCO, a putative metal ion transporter, is crucial for Plasmodium liver-stage development. EMBO Molecular Medicine 6, 1387-1397. https://doi.org/10.15252/emmm.201403868

Sayers, C.P., Mollard, V., Buchanan, H.D., McFadden, G.I., Goodman, C.D., 2018. A genetic screen in rodent malaria parasites identifies five new apicoplast putative membrane transporters, one of which is essential in human malaria parasites. Cellular Microbiology 20, e12789. https://doi.org/10.1111/cmi.12789

Semenovskaya, K., Lévêque, M.F., Berry, L., Bordat, Y., Dubremetz, J.-F., Lebrun, M., Besteiro, S., 2020. TgZFP2 is a novel zinc finger protein involved in coordinating mitosis and budding in Toxoplasma. Cellular Microbiology 22, e13120. https://doi.org/10.1111/cmi.13120

Seo, P.J., Park, J., Park, M.-J., Kim, Y.-S., Kim, S.-G., Jung, J.-H., Park, C.-M., 2012. A Golgi-localized MATE transporter mediates iron homoeostasis under osmotic stress in Arabidopsis. Biochem J 442, 551-561. https://doi.org/10.1042/BJ20111311

Sharma, P., Tóth, V., Hyland, E.M., Law, C.J., 2021. Characterization of the substrate binding site of an iron detoxifying membrane transporter from Plasmodium falciparum. Malar J 20, 295. https://doi.org/10.1186/s12936-021-03827-7

Sidik, S.M., Huet, D., Ganesan, S.M., Huynh, M.-H., Wang, T., Nasamu, A.S., Thiru, P., Saeij, J.P.J., Carruthers, V.B., Niles, J.C., Lourido, S., 2016. A Genome-wide CRISPR Screen in Toxoplasma Identifies Essential Apicomplexan Genes. Cell 166, 1423-1435.e12. https://doi.org/10.1016/j.cell.2016.08.019

Sigala, P.A., Crowley, J.R., Hsieh, S., Henderson, J.P., Goldberg, D.E., 2012. Direct Tests of Enzymatic Heme Degradation by the Malaria Parasite Plasmodium falciparum*. Journal of Biological Chemistry 287, 37793-37807. https://doi.org/10.1074/jbc.M112.414078

Slavic, K., Krishna, S., Lahree, A., Bouyer, G., Hanson, K.K., Vera, I., Pittman, J.K., Staines, H.M., Mota, M.M., 2016. A vacuolar iron-transporter homologue acts as a detoxifier in Plasmodium. Nature Communications 7, 10403. https://doi.org/10.1038/ncomms10403

Smyth, D.J., Glanfield, A., McManus, D.P., Hacker, E., Blair, D., Anderson, G.J., Jones, M.K., 2006. Two Isoforms of a Divalent Metal Transporter (DMT1) in Schistosoma mansoni Suggest a Surface-associated Pathway for Iron Absorption in Schistosomes. J Biol Chem 281, 2242-2248. https://doi.org/10.1074/jbc.M511148200

Sorribes-Dauden, R., Peris, D., Martínez-Pastor, M.T., Puig, S., 2020. Structure and function of the vacuolar Ccc1/VIT1 family of iron transporters and its regulation in fungi. Computational and Structural Biotechnology Journal 18, 3712-3722. https://doi.org/10.1016/j.csbj.2020.10.044

Striepen, B., Jordan, C.N., Reiff, S., Dooren, G.G. van, 2007. Building the Perfect Parasite: Cell Division in Apicomplexa. PLOS Pathogens 3, e78. https://doi.org/10.1371/journal.ppat.0030078 
Tang, Y., Guest, J.R., 1999. Direct evidence for mRNA binding and post-transcriptional regulation by

Escherichia coli aconitases. Microbiology (Reading) 145 ( Pt 11), 3069-3079. https://doi.org/10.1099/00221287-145-11-3069

Tanveer, A., Allen, S.M., Jackson, K.E., Charan, M., Ralph, S.A., Habib, S., 2013. An FtsH Protease Is

Recruited to the Mitochondrion of Plasmodium falciparum. PLOS ONE 8, e74408. https://doi.org/10.1371/journal.pone.0074408

Thipubon, P., Uthaipibull, C., Kamchonwongpaisan, S., Tipsuwan, W., Srichairatanakool, S., 2015.

Inhibitory effect of novel iron chelator, 1-(N-acetyl-6-aminohexyl)-3-hydroxy-2-methylpyridin-4-one

(CM1) and green tea extract on growth of Plasmodium falciparum. Malar J 14, 382. https://doi.org/10.1186/s12936-015-0910-1

Thuma, P.E., Olivieri, N.F., Mabeza, G.F., Biemba, G., Parry, D., Zulu, S., Fassos, F.F., McClelland, R.A., Koren, G., Brittenham, G.M., Gordeuk, V.R., 1998. Assessment of the effect of the oral iron chelator deferiprone on asymptomatic Plasmodium falciparum parasitemia in humans. Am J Trop Med Hyg 58, 358364. https://doi.org/10.4269/ajtmh.1998.58.358

Veenemans, J., Milligan, P., Prentice, A.M., Schouten, L.R.A., Inja, N., Heijden, A.C. van der, Boer, L.C.C. de, Jansen, E.J.S., Koopmans, A.E., Enthoven, W.T.M., Kraaijenhagen, R.J., Demir, A.Y., Uges, D.R.A., Mbugi, E.V., Savelkoul, H.F.J., Verhoef, H., 2011. Effect of Supplementation with Zinc and Other Micronutrients on Malaria in Tanzanian Children: A Randomised Trial. PLOS Medicine 8, e1001125. https://doi.org/10.1371/journal.pmed.1001125

Vignesh, K.S., Deepe, G.S., 2016. Immunological Orchestration of Zinc Homeostasis: The Battle between Host Mechanisms and Pathogen Defenses. Arch Biochem Biophys 611, 66-78. https://doi.org/10.1016/j.abb.2016.02.020

Wang, J., Pantopoulos, K., 2011. Regulation of cellular iron metabolism. Biochem J 434, 365-381. https://doi.org/10.1042/BJ20101825

Xiao, G., Wan, Z., Fan, Q., Tang, X., Zhou, B., 2014. The metal transporter ZIP13 supplies iron into the secretory pathway in Drosophila melanogaster. eLife 3, e03191. https://doi.org/10.7554/eLife.03191

Yamasaki, S., Shoji, M., Kayanuma, M., Sladek, V., Inaoka, D.K., Matsuo, Y., Shiba, T., Young, L., Moore, A.L., Kita, K., Shigeta, Y., 2021. Weak O2 binding and strong H2O2 binding at the non-heme diiron center of trypanosome alternative oxidase. Biochimica et Biophysica Acta (BBA) - Bioenergetics 1862, 148356. https://doi.org/10.1016/j.bbabio.2020.148356

Zhang, M., Wang, C., Otto, T.D., Oberstaller, J., Liao, X., Adapa, S.R., Udenze, K., Bronner, I.F., Casandra, D., Mayho, M., Brown, J., Li, S., Swanson, J., Rayner, J.C., Jiang, R.H.Y., Adams, J.H., 2018. 
631 modulate iron translocation between flag leaves and seeds in rice. Plant J 72, 400-410. 632 https://doi.org/10.1111/j.1365-313X.2012.05088.x

633 Zhu, X., Boulet, A., Buckley, K.M., Phillips, C.B., Gammon, M.G., Oldfather, L.E., Moore, S.A., Leary, 634 S.C., Cobine, P.A., 2021. Mitochondrial copper and phosphate transporter specificity was defined early in the 635 evolution of eukaryotes. eLife 10, e64690. https://doi.org/10.7554/eLife.64690 636 637 638 639 640 